\title{
Estimativa de fluxo de calor latente em reservatórios através de uma rede neural artificial
}

\author{
Estimating latent heat flux over reservoirs using an artificial neural network
}

\author{
Dornelles Vissotto Junior, Lucas Emílio Bernardelli Hoeltgebaum, Ricardo Carvalho de Almeida \\ Universidade Federal do Paraná \\ dvissotto@gmail.com; lucas.emilio@ufpr.br; rcalmeida@ufpr.br
}

\begin{abstract}
Resumo
O monitoramento micrometeorológico é utilizado em reservatórios para a medição dos fluxos de calor latente através do método de covariâncias turbulentas. É difícil estabelecer séries longas e contínuas de medição devido à complexidade envolvida no monitoramento. Quando ocorrem falhas é necessário o preenchimento das lacunas para manter a continuidade da série. Este preenchimento pode ser realizado através de técnicas estatísticas e resultados de modelos. Neste trabalho foi avaliado o desempenho do modelo de Redes Neurais Artificiais (RNA) backpropagation para as estimativas do fluxo de calor latente no lago de FurnasMG para o preenchimento das falhas em dados medidos durante 50 dias. A RNA foi aplicada utilizando vários conjuntos de parâmetros de entrada, estrutura de camadas e tempo de treinamento. O desempenho das estimativas do RNA foram comparadas com o desempenho de um modelo clássico de transferência de massa (MOD). Para avaliar o desempenho dos modelos foi utilizado $o$ indice de concordância de willmott. O modelo de RNA obteve um indice de concordância de 0,93536, apresentando resultados melhores que o modelo de tranferência com 0,89681 . Os resultados demonstraram que a RNA poder ser utilizada com grande sucesso para a estimativa de fluxo de calor latente
\end{abstract}

Palavras-chave: fluxo de calor latente, lagos, redes neurais, covariâncias turbulentas, micrometeorologia.

\begin{abstract}
Micrometeorology monitoring has been used in reservoirs for latent heat flux measurements by eddy covariance. It is hard to establish long and continuous measurement datasets due to the complexity involved in this monitoring. When fails occur there is necessary a gap filling procedure to keep the continuity of the series. This filling could be performed through statistical techniques and use of model results. In this work we assessed the performance of a backpropagation Artificial Neural Network (ANN) Model to estimatives of latent heat fluxes at Furnas Lake - MG to fill the gaps in 50 days measurement dataset. The ANN was applied using various sets of input parameters, layer structures and trainning time. The performance of ANN estimatives were compared of a classic mass transfer model. The index of agreement are used to evaluate the performance of the models. The ANN Model index of agreement equal to 0.93536 showing better results than transfer model with 0.89681 . The results showed that the ANN could be used with great performance to estimate latent heat flux and gap filling.
\end{abstract}

Keywords: latent heat flux, lakes, neural network, eddy covariance, micrometeorology. 


\section{Introdução}

\subsection{Método de covariâncias turbulentas}

O monitoramento micrometeorológico tem sido utilizado como uma importante ferramenta na análise dos dados ambientais, em especial a medição de fluxos superficiais através do método de covariâncias turbulentas ou eddy covariance (Dias et al., 2002; Aubinet et al., 2012; Scientifc, 1996; Lee et al., 2004). Muitos problemas ocorrem com o monitoramento por covarâncias turbulentas devido a complexidade dos sensores envolvidos no método. Problemas como os efeitos devido a sensibilidade dos sensores, pista de vento e advecção ainda afetam os dados e alguns estudos ao longo dos anos vem buscando aperfeiçoar o método de medição corrigindo estas falhas.

Os dados de fluxo de calor latente utilizados neste trabalho foram obtidos pelo LEMMA-UFPR (Laboratório de Monitoramento e Modelagem Ambientais) durante o período de 22/07/2004 a 14/09/2004 em uma campanha realizada sobre o Lago de Furnas - MG. Foram utilizados os sensores anemômetro sônico CAMPBELL CSAT e o Termohigrômetro LICOR LI7500. Os dados foram obtidos a uma frequência de $20 \mathrm{~Hz}$, analisados, processados e armazenados em médias de flutuações a cada $30 \mathrm{~min}$.

Após a aplicação de técnicas de correção e filtragem eliminando os dados fisicamente inconsistentes (outliers, Vissotto Jr. e Dias (2013)), os efeitos devido a sensibilidade dos sensores, pista de vento e advecção (Vissotto Jr et al., 2009; Cancelli et al., 2012) a série de dados fica com lacunas que precisam ser preenchidas.

\subsection{Redes Neurais Artificiais}

Uma Rede Neural Artificial (RNA) é um sistema de processamento de informações com características semelhantes ao sistema neural biológico, ou seja, com elementos receptores e transmissores de informação (neurônios) através de ligações (sinapse) em que cada uma possui um certo peso associado para sua transmissão (pesos), finalizando com uma certa função de ativação (Fausett, 1994). O uso de redes neurais se dá por sua capacidade de generalizar problemas (modelos) matemáticos ou fenômenos naturais que possuam alguma recorrência dada pelas variação dos sinais nos neurônios de entrada (inputs).

RNA's são classificadas de várias formas, entre elas por sua arquitetura (camada única, múltipla ou competitiva) ou pelo tipo de treinamento (supervisionado ou não-supervisionado) (Fausett, 1994). A rede escolhida para este trabalho foi uma RNA de retropropagação (backpropagation) que possui múltiplas camadas (três, neste caso, a de entrada, oculta e de saída). Este é o tipo

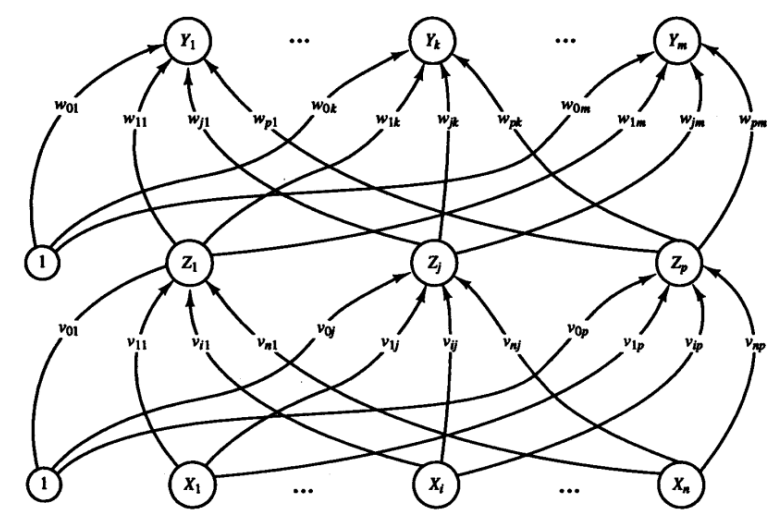

Figura 1: RNA backpropagation com uma camada oculta. Fonte: Fausett (1994).

de rede muito utilizado em problemas que envolvam previsão com séries temporais (Mishra e Desai, 2006).

O treinamento desse tipo de rede consiste na propagação dos sinais da camada de entrada para a demais através dos respectivos pesos, sendo a resposta comparada com o alvo esperado (que pode possuir mais de uma dimensão). A diferença nos resultados é utilizada para corrigir os pesos entre a camada oculta e de saída através da regra delta generalizada. Após a correção, uma nova época (ciclo) de treinamento é iniciada para cada par (entrada(s)-alvo(s)) e novas correções são feitas e os pesos das conexões sinápticas entre os neurônios são atualizados. O treinamento termina quando o erro atinge um valor mínimo estabelecido. A figura 1 mostra o esquema geral de uma RNA backpropagation.

Muitos trabalhos têm sido desenvolvidos com o uso de redes neurais, especialmente para previsão de algum fenômeno de interesse ambiental e suas motivações variam, mas em geral estão ligadas às dificuldades de modelagem associadas à não-linearidade de muitos destes problemas, o que muitas vezes é superado de forma relativamente satisfatória pelas RNA's.

Mishra e Desai (2006) aplicaram duas redes neurais backpropagation, sendo uma recursiva e outra direta para a previsão de secas na bacia do rio Kansabati, Índia, e assim comparar com os modelos ARIMA/SARIMA, sendo ambos os métodos alimentados com dados do índice SPI para quantificar a seca. Para diferentes tempos de previsão, o modelo se comportou melhor que a RNA, no entano a rede neural foi mais eficaz para previsões de curto prazo (menos de quatro meses), em que ocorreu um menor acúmulo de erros.

van Wijk e Bouten (1999) usaram RNA's para modelar os fluxos de vapor d'água (calor latente) e dióxido de carbono sobre florestas de coníferas na Europa. Foi utilizada uma rede backpropagation com uma camada oculta em que foram testadas várias arquiteturas a fim de se conhecer as variáveis meteorológicas mais importantes 
nestes processos. Os resultado para um curto prazo de previsão destas duas variáveis foram satisfatórios, mesmo não discriminando na modelagem as características fisiológicas das árvores e informações específicas de cada site.

Ainda na área de modelagem de fluxos de dióxido de carbono, Melesse e Hanley (2005) aplicaram uma rede neural multicamadas perceptron na tentativa de se obter essas estimativas a partir de outras variáveis micrometeorológicas medidas através do método de covariâncias turbulentas sobre três tipos diferentes de ecossistemas, obtendo uma boa correspondência entre os dados observados e modelados.

As RNA's também têm sido aplicadas na área de micrometeorologia para desenvolvimento de novas técnicas de preenchimento de falhas nas séries temporais. ((Schmidt et al., 2008) e (Ooba et al., 2006)). Este trabalho avaliou a utilização do modelo de Redes Neurais Artificiais (RNA) backpropagation como alternativa para o preenchimento das séries temporais de fluxo de calor latente do lago de Furnas com dados artificiais.

\section{Metodologia}

O uso de RNA's para a previsão de um fenômeno qualquer envolve dois passos importantes: o treinamento com dados de entrada (input) e saída (alvo) medidos e observados; e a operação com os dados de entrada medidos, utilizando-se das sinapses geradas no processo de treinamento. Este trabalho focou seus esforços na primeira etapa, a fim de se conhecer a viabilidade da RNA para este fenômeno, e posteriomente, em trabalhos futuros, fazer algumas análises de operação.

Foram utilizados 2406 dados contínuos coletados em uma estação micrometeorológica, instalada no reservatório de Furnas, em Minas Gerais, entre as 15:00 do dia 22 de Julho de 2004 e as 20:00 do dia 11 de Setembro de 2004. A descrição dos sensores e do local de medição são bem detalhados por Cancelli et al. (2012).

Os dados foram processados e suas estatísticas médias de 30 minutos foram armazenadas (Dias et al., 2008). Os dados foram filtrados para selecionar a melhor pista de vento (Dias et al., 2010) e eliminar os problemas de medição (Vissotto Jr et al., 2009). As flutuações de umidade foram corrigidas de acordo com a metodologia de Web et al. (1980). Foi aplicado o controle de qualidade proposto por Foken et al. (2004) e utilizado o método para eliminação dos outliers proposto por Vissotto Jr. e Dias (2013).

Foram obtidos 1134 dados consistentes e confiáveis a cada trinta minutos das três direções da velocidade do vento $-u, v$ e $w\left(\mathrm{~ms}^{-1}\right)$ - temperatura do ar dada pelo anemômetro sônico e pelo termopar $-t_{s}$ e $t_{e}$, respectivamente $\left({ }^{\circ} \mathrm{C}\right)$ - umidade específica e a temperatura na superfície da água $-T_{0}\left({ }^{\circ} \mathrm{C}\right)$.

O fluxo de calor latente $L E\left(\mathrm{Wm}^{-2}\right)$ pode ser então calculado como:

$$
L E=L \bar{\rho} \overline{w^{\prime} q^{\prime}} \equiv u_{*} q_{*}
$$

onde $L$ é o calor latente de evaporação, $\bar{\rho}$ é a densidade do ar e $\overline{w^{\prime} q^{\prime}}$ a covariância turbulenta entre a velocidade vertical $w$ e a umidade específica $q$. Usualmente a barra sobreposta indica a média e os apóstrofes indicam as flutuações turbulentas. $u_{*}$ é a velocidade de atrito e $q_{*}$ é a escala turbulenta de umidade na camada superficial.

O cálculo de $L E$ pelo modelo de transferência pode ser definido como

$$
E=\bar{\rho} C_{E} \bar{u}_{b}\left(\bar{q}_{0}-\bar{q}_{a}\right)
$$

O subscrito $b$ denota a altura de medição de vento $\left(z_{b}\right)$ para a velocidade horizontal $u ; a$ denota a altura de medição de escalares $\left(z_{a}\right)$ e o subscrito 0 indica a altura do nível de água $(z=0)$.

O coeficiente de transferência estabelecido pela Teoria de Similaridade de Monin-Obukhov é

$$
C_{E}=\frac{\kappa^{2}}{\left[\ln \left(\frac{z_{b}}{z_{0 \tau}}\right)-\Psi_{\tau}\left(\frac{z_{b}}{L_{O}}\right)\right]\left[\ln \left(\frac{z_{a}}{z_{0 E}}\right)-\Psi_{E}\left(\frac{z_{a}}{L_{O}}\right)\right]},
$$

com

$$
\begin{aligned}
& z_{0 \tau}=a_{M} \frac{u_{*}^{2}}{g}, \\
& z_{0 E}=a_{E} z_{0 \tau} \exp \left(-b_{E} \mathcal{K}\left(\frac{u_{*} z_{0 \tau}}{v}\right)^{1 / 4} \mathrm{Sc}^{1 / 2}\right),
\end{aligned}
$$

onde $v$ é a viscosidade cinemática do ar, $\mathrm{Pr}=0.713$ é o número de Prandtl para o ar e $\mathrm{Sc}=0.595$ é o número de Schmidt para o vapor d'água no ar (ambos a $20^{\circ} \mathrm{C}$ ). Em (3), os $\Psi^{\prime}$ 's são a integral da função de estabilidade para momento e para vapor d'água, $L_{0}$ é o comprimento de Obukhov e os $z_{0}$ 's são os correspondentes comprimentos de rugosidade (Brutsaert, 1975b,a). Nas equações (4-5) os coeficientes para superfícies líquidas são $a_{M}=0.016$, $a_{E}=7.4$ e $b_{E}=7.3$.

Da série de dados resultantes do processo de correção e filtragem (1134 dados), aproximadamente 70\% foram utilizadas para treinamento da rede, $15 \%$ para teste e $15 \%$ para validação sendo estes dois últimos utilizados para apresentação das estatísticas e avaliação do desempenho da RNA.

Vários testes foram realizados com a intenção de se verificar quais variáveis medidas são as melhores preditoras do fluxo de calor latente. Conforme demonstrado, todas as variáveis medidas pelo conjunto citado são fundamentais para o cálculo do $L E$, no entanto, para aplicação da RNA é interessante empregar uma arquitetura que se permita entrar com o menor número de dados medidos, obtendo-se o melhor resultado possível. 
Neste trabalho para a rede proposta por Fausett (1994) mostrada na figura 1 foram variados os números de neurônios na camada de entrada $\left(X_{n}\right)$ e na camada oculta $\left(Z_{p}\right)$. Para a saída foi considerado um único neurônio, que será a resposta esperada $Y_{m}$ para o fluxo de calor latente.

Para isto, inicialmente, foram testados 10 conjuntos de treinamento e em cada um foram variados a arquitetura da rede, o número máximo de época de treinamento e a taxa de aprendizagem, utilizando diferentes combinações de variáveis de entrada.

\section{Resultados e Discussões}

O comparativo de resultados de modelos nem sempre é elementar (Willmott, 1982; Nash e Sutcliffe, 1970). É necessário estabelecer quanto os resultados dos modelos está próximo dos dados observados (concordância) bem como quanto os resultados de um modelo são melhores que os resultados de outro modelo (eficiência). Este comparativo é uma análise sensitiva de determinação do quanto a razão entre a diferenças nos resultados de modelagem são afetados pelas mudanças nos parâmetros de entrada dos modelos.

Utilizar parâmetros estatísticos paramétricos como a regressão por mínimos quadrados estabelece o quanto o resultado do modelo está variando estatisticamente dos dados medidos, porém, não estabelece por si só um parâmetro comparativo entre os desempenhos de cada simulação de um modelo, pois seus resultados são em termos dos valores absolutos.

Nash e Sutcliffe (1970) propuseram uma abordagem sistemática no sentido de desenvolver, testar e modificar um modelo para um conjunto de parâmetros de entrada através de uma medida de eficiência normalizada. Esta medida é baseada na numa estimativa do índice de não concordância do modelo, análogo a variância residual, e da variância inicial do modelo. A eficiência de NashSutcliffe (NSE) caracterizada por Moriasi et al. (2007), é expressa por:

$$
\mathrm{NSE}=1-\frac{\sum_{i}^{N}\left(O_{i}-P_{i}\right)^{2}}{\sum_{i}^{N}\left(O_{i}-\bar{O}\right)^{2}}
$$

onde $P_{i}$ é o valor estimado pelo modelo para o valor observado $O_{i}$ e $\bar{O}$ é a média das $N$ observações. O índice de eficiência pode variar entre - inf e 1 , sendo que quanto mais próximo de 1 mais eficiente é a modelagem.

Visando estabelecer um índice de concordância normalizado (index of agreement) Willmott (1981) propôs um índice semelhante ao NSE que têm se mostrado versátil
(Willmott et al., 2012), e é expresso por:

$$
d=1-\frac{\sum_{i}^{N}\left(P_{i}-O_{i}\right)^{2}}{\sum_{i}^{N}\left[\left|P_{i}-\bar{O}\right|+\left|O_{i}-\bar{O}\right|\right]^{2}} .
$$

O índice de concordância pode variar entre 0 e 1 , sendo que quanto mais próximo for de 1 melhor é a concordância do modelo com o observado.

Na tabela 1 estão listados todos os conjuntos de treinamento e o melhor resultado obtido em cada um deles comparando os índices de eficiência NSE e de concordância $d$.

Tabela 1: Conjuntos de testes (T), variáveis de entrada utilizadas e melhor arquitetura (ARQ) baseando-se nos coeficientes de eficiência de Nash-Sutcliffe (NSE) e índice

\begin{tabular}{|c|c|c|c|}
\hline $\mathrm{T}$ & ARQ & Variáveis & \\
\hline \multirow{2}{*}{1} & \multirow{2}{*}{ 6-3-1 } & $u, v, w$ & NSE: 0,618 \\
\hline & & $t_{s}, t_{e}, q$ & $d: 0,914$ \\
\hline 2 & $3-10-1$ & $u, v, w$ & $\begin{array}{r}\text { NSE: } 0,387 \\
d: 0,869\end{array}$ \\
\hline 3 & $3-6-1$ & $t_{e}, q, T_{0}$ & $\begin{array}{r}\text { NSE: } 4,325 \\
d: 0,800\end{array}$ \\
\hline 4 & $1-3-1$ & $q$ & $\begin{array}{r}\text { NSE: }-0,36 \\
d: 0,782\end{array}$ \\
\hline 5 & $1-3-1$ & $\overline{w^{\prime} q^{\prime}}$ & $\begin{array}{r}\text { NSE: } 0,999 \\
d: 0,999\end{array}$ \\
\hline 6 & 7-4-1 & $\begin{array}{l}u, v, w \\
t_{s}, t_{e}, q, T_{0}\end{array}$ & $\begin{array}{r}\text { NSE: } 0,718 \\
d: 0,935\end{array}$ \\
\hline 7 & $5-10-1$ & $\begin{array}{l}u, t_{s}, t_{e} \\
q, T_{0}\end{array}$ & $\begin{array}{r}\text { NSE: } 0,583 \\
d: 0,899 \\
\end{array}$ \\
\hline 8 & $5-10-1$ & $\begin{array}{l}v, t_{s}, t_{e} \\
q, T_{0}\end{array}$ & $\begin{array}{r}\text { NSE: } 0,467 \\
d: 0,883 \\
\end{array}$ \\
\hline 9 & $5-15-1$ & $\begin{array}{l}w, t_{s}, t_{e} \\
q, T_{0}\end{array}$ & $\begin{array}{r}\text { NSE: } 0,391 \\
\quad d: 0,880\end{array}$ \\
\hline 10 & 7-9-1 & $\begin{array}{l}\sqrt{u^{2}+v^{2}}, w, t_{e} \\
q, U R, e s_{0}, e_{s 0}-e\end{array}$ & $\begin{array}{r}\text { NSE: } 0,781 \\
\quad d: 0,935\end{array}$ \\
\hline
\end{tabular}
de concordância de Willmott $d$.

O teste 5 na tabela 1 foi utilizado apenas como referencial para o modelo RNA, pois o método de covariâncias turbulentas utiliza a covariância entre a velocidade vertical $w$ e a umidade específica $q$ para o cálculo do fluxo de calor latente, conforme a equação (1). Deste modo pode-se perceber que a RNA possui um bom esquema de treinamento.

Na tabela 1, UR é a umidade relativa do ar em $z_{a}$, e $e_{\mathrm{S} 0} \mathrm{e} e$ são as pressões de vapor na superfície do lago e em $z_{a}$, respectivamente, calculadas com os dados medidos.

A figura 2 mostra os resultados comparativos do modelo de RNA e do modelo de tranferência (MOD). 


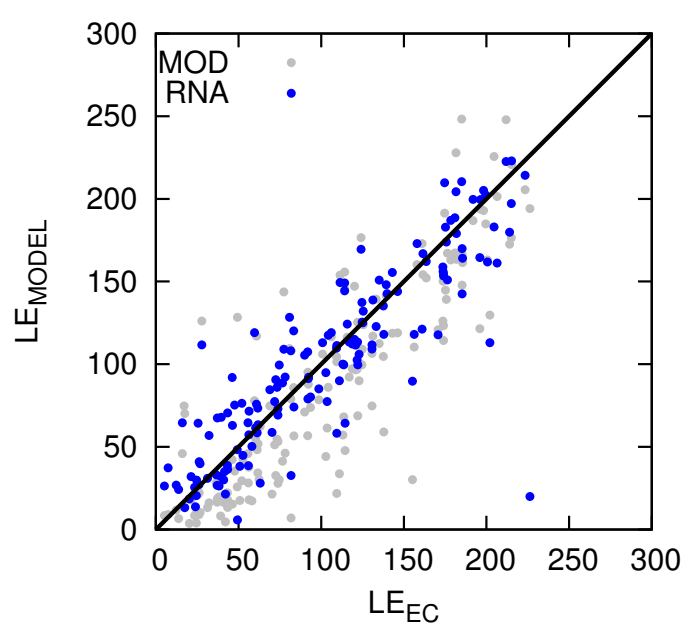

Figura 2: Resultados comparativos dos modelos de transferência (MOD, em cinza) e de Redes Neurais Artificiais (RNA, em azul) com relação a medição.

Os resultados se apresentaram muito satisfatórios.

A eficiência NSE dos modelos estabelecido pela equação 6 foi de 0,64764 para o MOD e de 0,78127 para o RNA. O índice de concordância $d$ dos modelos estabelecido pela equação 7 foi de 0,89681 para o MOD e de 0,93536 para o RNA. A tabela 2 mostra ainda as análises estatísticas de raiz do erro médio quadrático (RMSE) e coeficiente de correlação de Pearson (pearson), evidenciando que o modelo RNA apresenta um melhor resultado para a previsão do fluxo de calor latente.

Tabela 2: Estatíticas dos Modelos.

\begin{tabular}{lrr}
\hline Estatística & MOD & RNA \\
\hline NSE & 0.64764 & 0.78127 \\
\hline$d$ & 0.89681 & 0.93536 \\
\hline pearson & 0.81796 & 0.88418 \\
\hline RMSE & 40.95421 & 32.26706 \\
\hline
\end{tabular}

Apesar de apresentar melhores resultados, restam ainda nas estimativas de RNA alguns pontos que se distanciam muitam da reta 1:1, em especial o ponto $(226.320,19.982)$, que mesmo após tendo os dados aprovados nos testes e filtros aplicados, a estimativa foi muito divergente e os dados devem ser novamente investigados. Com resultados satisfatórios para um pequeno conjunto de dados, a RNA precisa ser avaliada para o uso em séries de dados mais longas e com outros conjuntos de dados, para uma validação do método.

\section{Conclusões}

Observando a figura 2 pode-se perceber que o espalhamento dos pontos em torno da reta 1:1 é menor para RNA que para MOD, indicando que RNA é um modelo que apresenta melhor concordância, ou seja, melhores estimativas e uma menor dispersão do erro, evidenciado pelas estatísticas da tabela 2, sendo um modelo mais eficiente para a previsão de $L E$ se comparado MOD, conforme avaliado pelo NSE.

Ao se empregarem variáveis processadas de umidade relativa $U R$ e de pressão de vapor de saturação $e_{S}$ diretamente na entrada da rede neural, em lugar de apenas valores de temperatura e umidade específica, foi possível melhorar o desempenho da rede para os testes do conjunto $\mathrm{T}=10$. Além disso, a velocidade vertical também mostrou ser uma variável de significativa importância para o cálculo do fluxo de calor latente.

O modelo de Redes Neurais backpropagation se mostrou eficiente para a estimativa de fluxo de calor latente, apresentado resultados melhores que o modelo clássico de transferência para a série de dados estudada. A aplicação do método é fácil e os resultados após a fase de treinamento podem ser processados com muita rapidez. Novos experimentos com modelos RNA devem ser realizados utilizando série mais longas e com novos conjuntos de dados a fim de realizar uam avaliação mais completa do desempenho desses modelos na estimativa de fluxo de calor latente.

\section{Agradecimentos}

Agradecimentos ao Comitê Científico do IX Workshop Brasileiro de Micrometeorologia, ao Corpo Editorial da revista Ciência \& Natura, ao professor Nelson Luis Dias e ao LEMMA - Laboratório de Estudos em Monitoramento e Modelagem Ambiental pelo apoio científico. Os experimentos desta pesquisa foram financiados por FURNAS CENTRAIS ELÉTRICAS S.A. através do contrato $\mathrm{N}^{\circ} 14.265$ para o Fundo Setorial de Energia Elétrica Brasileiro.

\section{Referências}

Aubinet, M., Vesala, T., Papale, D. (Eds) (2012). Eddy Covariance: A Practical Guide to Measurement and Data Analysis. Springer, Dordrecht, Heidelberg, London, New York.

Brutsaert, W. (1975a). The roughness length for water vapor, sensible heat and other scalars. Journal of Atmospheric Science, 32, 2028-2031. 
Brutsaert, W. (1975b). A theory for local evaporation (or heat transfer) from rough and smooth surfaces at ground level. Water Resources Research, 11, 543-550.

Cancelli, D. M., Dias, N. L., Chamecki, M. (2012). Dimensionless criteria for the production-dissipation equilibrium of scalar fluctuations and their implications for scalar similarity. Water Resources Research, 48(10), URL http://dx.doi.org/10.1029/2012WR012127.

Dias, N. L., Kan, A., Grodzki, L., Sanchez, S. D., Vissotto Jr., D. (2002). O método de covariâncias turbulentas atenuadas (MCTA) para medição dos fluxos de calor sens ível e latente: aplicação ao lago de Itaipu e seu redor. Revista Brasileira de Recursos Hídricos, 7(1), 143-160.

Dias, N. L., Cancelli, D. M., Vissotto Jr., D. (2008). Desafios e lições da medição moderna de evaporação em grandes lagos. Em: CDROM Anais II Simpósio de Recursos Hídricos do Sul-Sudeste, Associação Brasileira de Recursos Hídricos.

Dias, N. L., Cancelli, D. M., Vissotto Jr., D. (2010). Directional analysis of over-lake water vapor and heat fluxes. Em: EOS Trans AGU 91(26) Meet. Am. Suppl., American Geophysical Union, Foz do Iguaçu, Brazil, pp. Abstract H21A-01.

Fausett, L. (1994). Fundamentals of Neural Networks: Architectures, Algorithms, and Applications. Prentice-Hall, Inc..

Foken, T., Göckede, M., Mauder, M., Mahrt, L., Amiro, B. D., Munger, J. W. (2004). Handbook of Micrometeorology. A Guide for Surface Flux Measurements, Kluwer, Dordrecht, Cap. Post-field data quality control, pp. 181-208.

Lee, X., Massman, W. J., Law, B. E. (Eds) (2004). Handbook of Micrometeorology. A Guide for Surface Flux Measurements. Kluwer, Dordrecht.

Melesse, A. M., Hanley, R. S. (2005). Artificial neural network application for multi-ecosystem carbon flux simulation. Ecological Modelling, 189, 305-314.

Mishra, A. K., Desai, V. R. (2006). Drougth forecasting using feed-forward recursive neural network. Ecological Modelling, 198, 127-138.

Moriasi, D. N., Arnold, J. G., Liew, M. W. V., Bingner, R. L., Harmel, R. D., Veith, T. L. (2007). Model evaluation guidelines for systematic quantification of accuracy in watershed simulations. Transactions of the ... , 50(3), 885-900, URL http://swat.tamu.edu/media/ 1312/moriasimodeleval.pdf, 0001-2351.
Nash, J., Sutcliffe, J. (1970). River flow forecasting through conceptual models part i - a discussion of principles. Journal of Hydrology, 10(3), 282 290, URL http: //www. sciencedirect.com/science/ article/pii/0022169470902556.

Ooba, M., Hirano, T., Mogami, J. I., Hirata, R., Fujinuma, Y. (2006). Comparisons of gap-filling methods for carbon flux dataset: A combination of a genetic algorithm and an artificial neural network. Ecological Modelling, 198(3-4), 473-486.

Schmidt, A., Wrzesinsky, T., Klemm, O. (2008). Gap filling and quality assessment of $\mathrm{co} 2$ and water vapour fluxes above an urban area with radial basis function neural networks. Boundary-Layer Meteorology, 126(3), 389-413.

Scientifc, C. (1996). Eddy correlation system: instruction manual. Campbell Scientifc, Inc., Logan, Utah, USA, $9^{\circ}$ edn.

Vissotto Jr., D., Dias, N. L. (2013). Método empírico para determinação de outliers em séries de fluxos de dados micrometeorológicos pós-processados. Ciência e Natura, Especial, 150-152.

Vissotto Jr, D., Dias, N. L., Cancelli, D. M. (2009). Uma avaliação sistemática das correções do método de covariâncias turbulentas atenuadas para a medição de evaporação em lagos. Em: Anais, CD-ROM XVIII Simpósio Brasileiro de Recursos hídricos, Associação Brasileira de Recursos hídricos.

Web, E. K., Pearman, G. I., Leuning, R. (1980). Correction of flux measurements for density effects due to heat and water vapor transfer. Quaterly Journal of Royal Meteorological Society, 106, 85-100.

van Wijk, M. T., Bouten, W. (1999). Water and carbon fluxes above european coniferous forest modelled with neural network. Ecological Modelling.

Willmott, C. J. (1981). On the validation of models. Physical Geography, 2(2), 184-194, URL http: //www . tandfonline.com/doi/abs/10.1080/ 02723646.1981 .10642213$.

Willmott, C. J. (1982). Some Comments on the Evaluation of Model Performance. Bulletin of the American Meteorological Society, 63, 1309-1369.

Willmott, C. J., Robeson, S. M., Matsuura, K. (2012). A refined index of model performance. International Journal of Climatology, 32(13), 2088-2094, URL http: //dx.doi.org/10.1002/joc. 2419. 